\title{
Source Harmonic Reduction using Passive Filter in Different Non-Linear Loaded Conditions
}

\author{
T.M. Thamizh Thentral, Ishan Kar, Kritika Raj, Tanya Sengupta, Shbham Kumar Bal
}

\begin{abstract}
Harmonics in general are defined as positive integer multiples of the fundamental frequency, which dominate an electrical system due to the presence of linear and non-linear components which include transformers, inductors, capacitors, long transmission lines also occur due to effects such as the Corona Effect. Harmonics also occur due to the presence of active loads, transmission phenomenon and base vectors. The presence of harmonics within a circuit causes the distortion of the generated waveforms of the supply voltage or frequency. This enables complete distortion of the output signal and waveforms. This article is an intricate case study on the designing procedure of different types of passive filters and their simulated results, used for the harmonics reduction at the source side considering different types of load at the receiving end, covering a wide area of distortion due to ambidextrous properties.
\end{abstract}

Keywords: Filter, Single-Tuned, Double-Tuned, Multi-Tuned, frequency

\section{INTRODUCTION}

In the modern era, the use of power electronics components has been seen in most of the consumer based industries. These components characterized by the ability to carry larger amount of power and compact in size prove to be very advantageous $t$ any system subjected to them, as the cost is comparatively affordable. These components work with an efficiency margin much greater than that of the older devices and also have a large contribution towards energy saving, along with the flexibility of controlling the circuits to a wider range [1]. In addition to these advantages, they also create harmonic pollution in the system, affecting the current and voltage waveforms from the source to the load.

Harmonics in general can be defined as the electrical disturbances in waveforms due to the effect of power quality, associated with the issues inside of a circuit[2]. The presence of harmonics within a circuit causes unexpected power losses over the tenure of the equipments, malfunctioning of protective devices and deviation from precision values in the

Revised Version Manuscript Received on 10, September 2019.

T.M. Thamizh Thentral, Assistant Professor, Department of Electrical and Electronics Engineering, SRM Institute of Science and Technology, Chennai, Tamilnadu, India (Email: thentral2kuna@gmail.com)

Ishan Kar, Student, Department of Electrical and Electronics Engineering, SRM Institute of Science and Technology, Chennai, Tamilnadu, India

Kritika Raj, Student, Department of Electrical and Electronics Engineering, SRM Institute of Science and Technology, Chennai, Tamilnadu, India

Tanya Sengupta, Student, Department of Electrical and Electronics Engineering, SRM Institute of Science and Technology, Chennai, Tamilnadu, India

Shbham Kumar Bal, Student, Department of Electrical and Electronics Engineering, SRM Institute of Science and Technology, Chennai, Tamilnadu, India case of metering equipment. They also cause interferences with the telephonic lines [3].

\section{POWER SYSTEM HARMONICS}

The production, transmission and the submission of voltage in a perfect sinusoidal wave with a frequency of 50 $\mathrm{Hz}$ is very important for the proper functioning of the entire system. But many factors involving the elements connected in the network, consumer loads the sinusoidal wave of the voltage and current is introduced with harmonics creating undesirable waveforms with their frequency proportionally multiple of the base frequency $(50 \mathrm{~Hz}$, considered as the fundamental frequency). The removal of these harmonics is a very essential part for the proper functioning and for efficient measurements, for the motive of removal of harmonics different kinds of filters are used. The most commonly used filters are the passive filters, they used simple components ( register, capacitors, and inductors) so the overall cost of the filtering circuit remains low and the desired output will be seen. In a given waveform the total harmonic distortion can be formulated by

$$
\begin{aligned}
& T H D_{V}=\frac{\sqrt{V_{n-2}^{\infty} V^{2}}}{V_{1}^{\infty}} \\
& T H D_{I}^{\infty}=\frac{\sqrt{n=2}}{I_{t}^{\infty}}
\end{aligned}
$$

\section{PASSIVE FILTERS}

Passive filters concurs large section of research and practical application in the modern scenario due to its high reliability, simple design within economic range[4]. If a signal including harmonics is considered, it will be observed that harmonics associated with those signal will be ranging of different frequencies. Passive filters are circuits made up of simple components such as reactors and capacitors which acts on the reduction of a single frequency or multiple frequencies in which the harmonics is induced. Depending on the application and the level of harmonics the filters can be classified as

1. Single Tuned Filters

2. Double Tuned Filters

3. Multi Tuned Filters 


\section{CONDITIONS}

\subsection{Single Tuned Filters}

A single tuned filtering circuit consists of RLC branch with each component connected in series to each other. The values of $\mathrm{R}, \mathrm{L}$ and $\mathrm{C}$ are so designed that it can tune a single harmonic frequency providing low impedance characters[5,6,].

$$
\begin{aligned}
& x_{x} \frac{1}{1} \\
& x_{2} \\
& R \\
& \frac{1}{=}
\end{aligned}
$$

Fig 1 Single tuned filter

When there are two or more harmonic frequencies needed to be tuned then those number of individual RLC filtering branch will be required. Each branch will be tuning a particular frequency and the value of these components should be individually calculated depending on the frequency it working on. However it increases the overall cost of the circuit $[7,8]$.

\subsection{Double Tuned Filter}

Unlike single tuned filters, double tuned filters affectively tunes two variant harmonics creating frequencies at once reducing the space and components of the circuits $[9,10]$.

A double tuned filter is made of serial resonating circuit to which a parallel resonating circuit will be connected. It is so

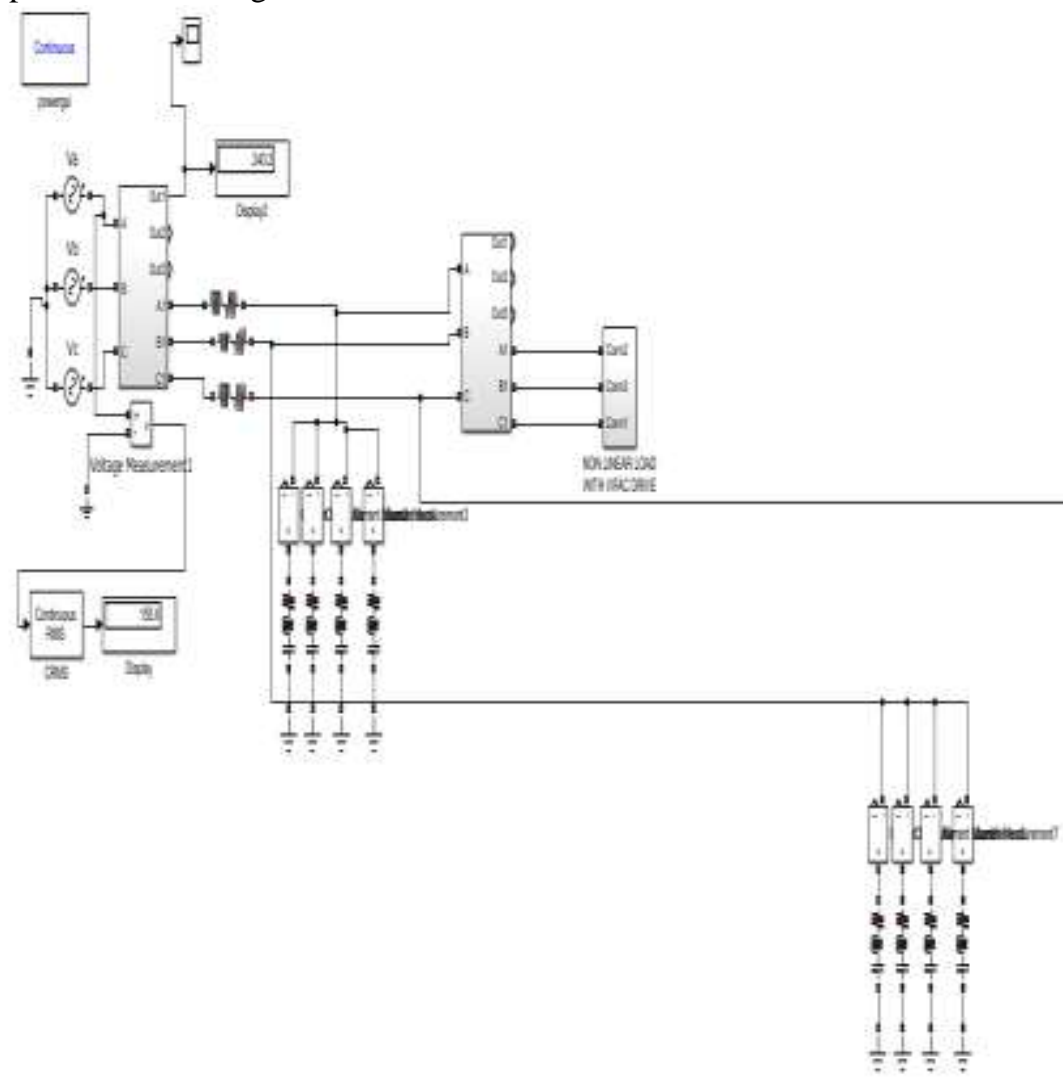

designed such that the series and the parallel resonating circuits will have dissimilar structure impendence graphs [10].

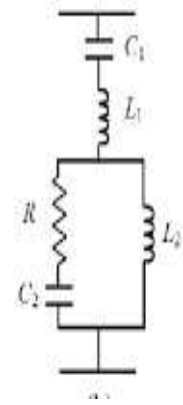

Fig 2 Double tuned filter

Fig 2 shows the double tuned circuit. L1 \& $\mathrm{C} 1$ acts as the series resonating circuit and L2 \& $\mathrm{C} 2$ will become the parallel resonating circuit.

\section{SIMULATION RESULTS}

All the simulations are performed using MATLAB software. A three phase circuit has been considered for the simulations along with line reactance, line impedance which are found in a practical transmission lines. Fig-3 shows the circuit for the simulation.

Fig-3 Circuit diagram without any load connected 
The simulation circuit which has been used for sampling of the output consists of three subsystems for monitoring various parameters which change in accordance to changing of various loads.

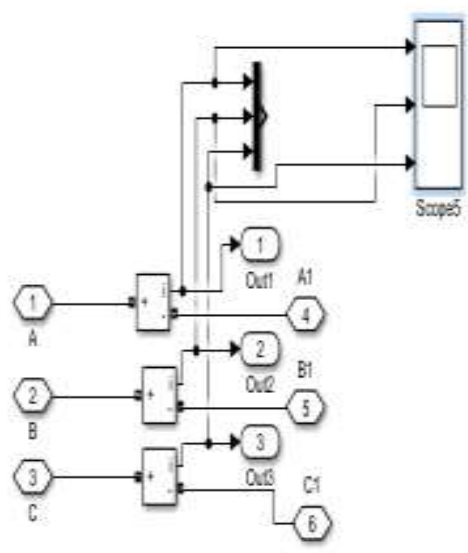

Fig-4 Sub-system-1

The fig-4 is the circuit diagram for monitoring the sub system 1 for of current in each phase which is to be measured before the transmission reactance and reluctance.

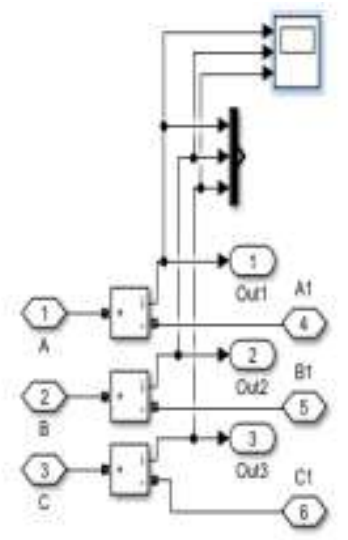

Fig-4 Sub-system-2

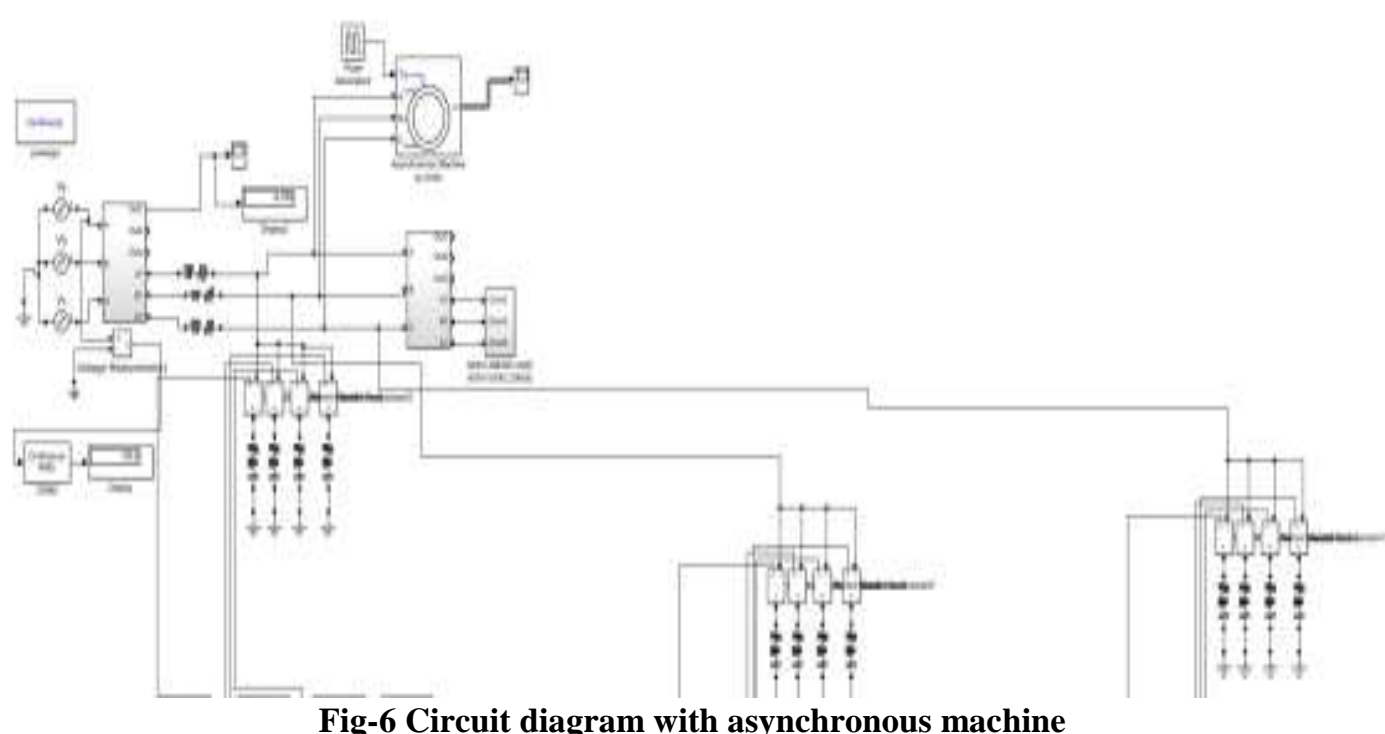

Fig-6 Circuit diagram with asynchronous machine

Fig-4 shows the subsystem 2 which is designed to monitor the current values after the transmission reactance and reluctance.

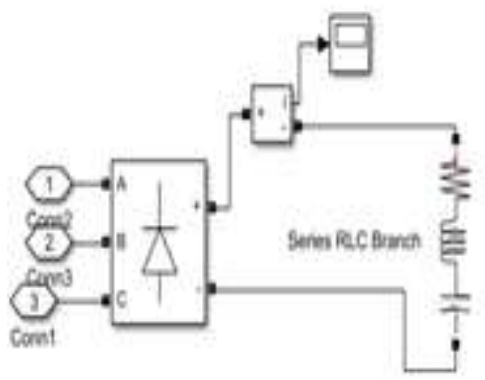

Fig-5 Sub-system-3

Fig-5 shows the circuitry connection inside the subsystem-3 which shows the rectified output and the dc part of the system.

\section{.1 Linear Load With Asynchronous Machine}

Asynchronous machine is a type of induction motor, in which torque is produced by rotor, with the influence of electromagnetic induction, in which the magnetic field is present in stator winding. The design of circuit subsist of veltage mearement block, non linear load, current measurement block, asynchronous machine, pulse generator, supply given to circuit is continuous. The supply voltage amplitude is $220 \mathrm{~V}$. Each phase comprises of non linear RLC filter. The RLC filter present in it curtails the total harmonic and voltage contortion. The fig- 6 shows the circuit use for the simulation. 


\section{SOURCE HARMONIC REDUCTION USING PASSIVE FILTER IN DIFFERENT NON-LINEAR LOADED CONDITIONS}

The block of asynchronous machine in simulink can work as both generator and motor. The operation is decided on the basis of the sign of mechanical torque(Tm). The machine will work as motor when Tm is positive else it will work as generator. 5The fundamental frequency which we have supplied is $50 \mathrm{HZ}$. By using RL filter in non-linear load the THD value is reduced to $18.61 \%$. The $3^{\text {rd }}$ harmonic is $7.64 \%$, $5^{\text {th }}$ harmonic is $4.50 \%, 7^{\text {th }}$ harmonic is $3.49 \%$. The fundamental peak is 43.69 at $30.9 \mathrm{rms}$ and the dc component obtained is $12.73 \mathrm{rms}$. The graph is produced with the help of FFT analysis. Tablr-1 gives the values of harmonics in a glance. The sample per cycle is 20025 .

\section{Total THD=1.24\%}

Table -1 THD \% for multiple of fundamental frequency

\begin{tabular}{|l|l|}
\hline Frequency & THD \\
\hline & \\
\hline $150 \mathrm{HZ}$ & $7.67 \%$ \\
\hline $250 \mathrm{HZ}$ & $4.50 \%$ \\
\hline $350 \mathrm{HZ}$ & $3.49 \%$ \\
\hline $450 \mathrm{HZ}$ & $2.65 \%$ \\
\hline $550 \mathrm{HZ}$ & $2.16 \%$ \\
\hline $650 \mathrm{HZ}$ & $1.82 \%$ \\
\hline $750 \mathrm{HZ}$ & $1.34 \%$ \\
\hline $850 \mathrm{HZ}$ & $0.91 \%$ \\
\hline
\end{tabular}

Fig-7 Machine Characteristics Vs Time for asynchronous machine

The graph in the fig-7 shows various parameters of the asynchronous machine monitored during operation of the machine, these parameters includes initial torque, speed, power factor, voltage and current curves etc. when compared with the ideal curve, the machine it can be seen the obtained graph I similarity with a little distortion in it.

\subsection{Linear load with dc motor}

Dc motor is a machine which converts the electrical to mechanical energy. Dc machine of the simulink block requires 3 phase voltages supply and dc voltage source. The pulse generator is attached to TL port of the dc machine and the scope will inturn shows the graph. The circuit abides universal bridge, pulse generator, dc machines and scope. The sub-components of dc machines involves four IGBT, RL, current measurement, voltage measurement, GoTo and from, pulse generator and scope. Fig- 8 shows the circuit diagram.

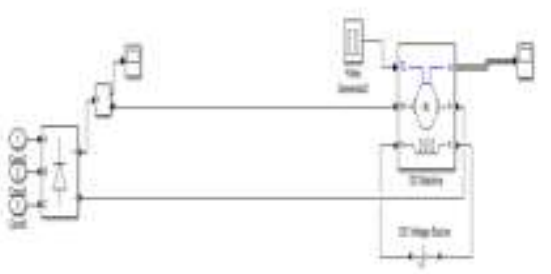

Fig-8 Sub system-3 with a DC machine load

The working of dc machines are as follows, at high pulse supply, the two alternate IGBT works simultaneously and the leftover IGBT's work at low pulse supply and the corresponding current and voltage measurements can be viewed on scope. B using linear load the THD value is reduced to $29.09 \%$. The $3^{\text {rd }}$ harmonic is $10.21 \%, 5^{\text {th }}$ harmonic is $11.17 \%$ and $9^{\text {th }}$ harmonic is $3.64 \%$. 


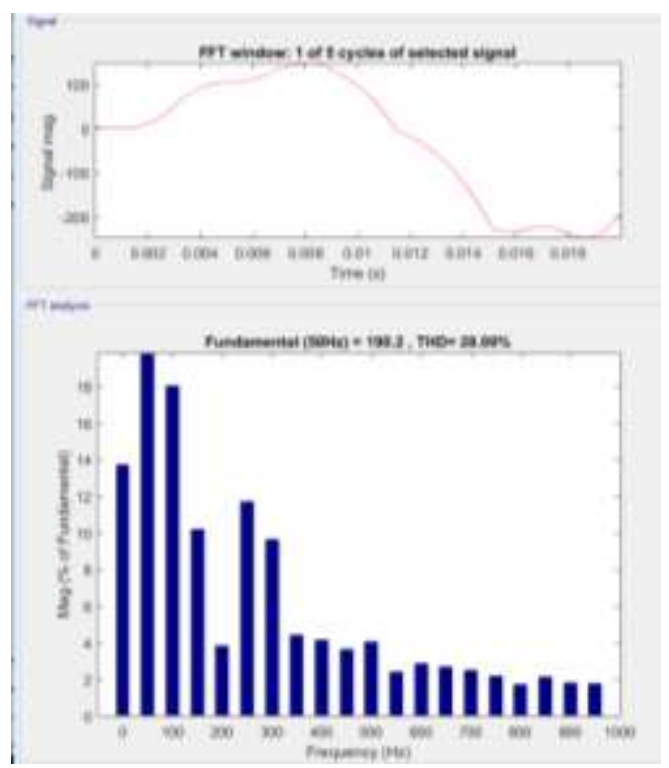

Fig-9 Harmonic destitution in accordance with fundamental frequency
The fundamental frequency and THD is shown using two different graphs described above.

Total $\mathbf{T H D}=\mathbf{2 8 . 0 9 \%}$

Table-2 THD\% for fundamental frequency with only linear load

\begin{tabular}{|l|l|}
\hline Frequency & THD \\
\hline $150 \mathrm{HZ}$ & $10.21 \%$ \\
\hline $250 \mathrm{HZ}$ & $11.71 \%$ \\
\hline $350 \mathrm{HZ}$ & $4.44 \%$ \\
\hline $450 \mathrm{HZ}$ & $3.64 \%$ \\
\hline $550 \mathrm{HZ}$ & $2.39 \%$ \\
\hline $650 \mathrm{HZ}$ & $2.68 \%$ \\
\hline $750 \mathrm{HZ}$ & $2.20 \%$ \\
\hline $850 \mathrm{HZ}$ & $2.13 \%$ \\
\hline $950 \mathrm{HZ}$ & $1.77 \%$ \\
\hline
\end{tabular}

The fundamental peak is obtained at 190.2 at $134.5 \mathrm{rms}$. The DC component is 26.08. The comparsion of the harmonic reduction between synchronous machine and dc motor shows that, the reduction is more in linear load with synchronous machine with THD of $18.61 \%$.

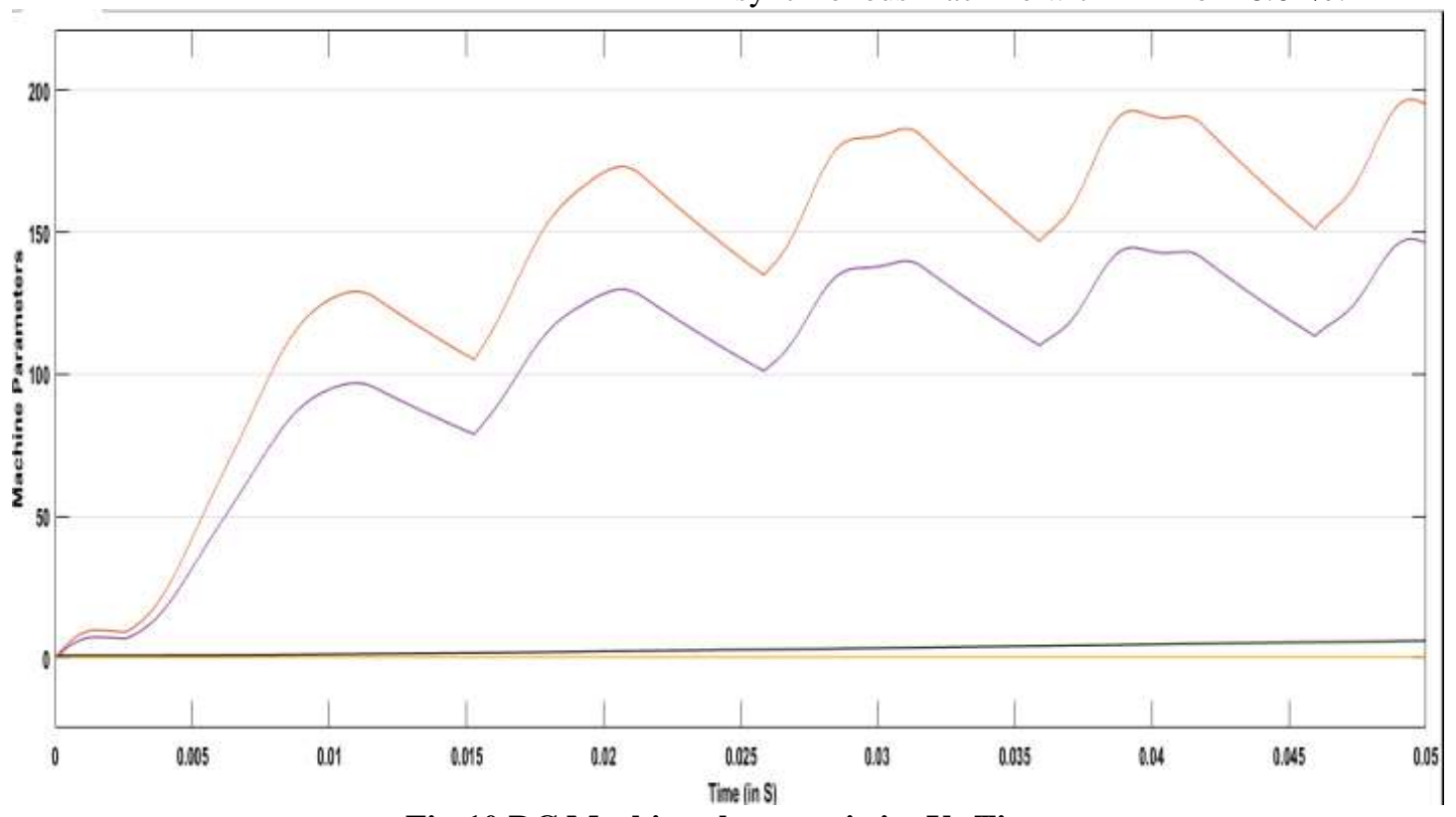

Fig-10 DC Machine characteristics Vs Time

The fig-10 gives the output of the dc machine considered. The graphs obtained shows that the machine has a little deviation form its ideal graph due to he presence of harmonics in the system.

\subsection{Linear Load With Inverter}

Inverter is basically a device which is use to transform direct current to alternating current at given voltage and frequency. The circuits consist of universal bridge, four IGBT, current measurement, voltage measurement, scope and RL. The value taken of resistance is $100 \mathrm{ohm}$ and inductance is $47 \mathrm{mH}$. 


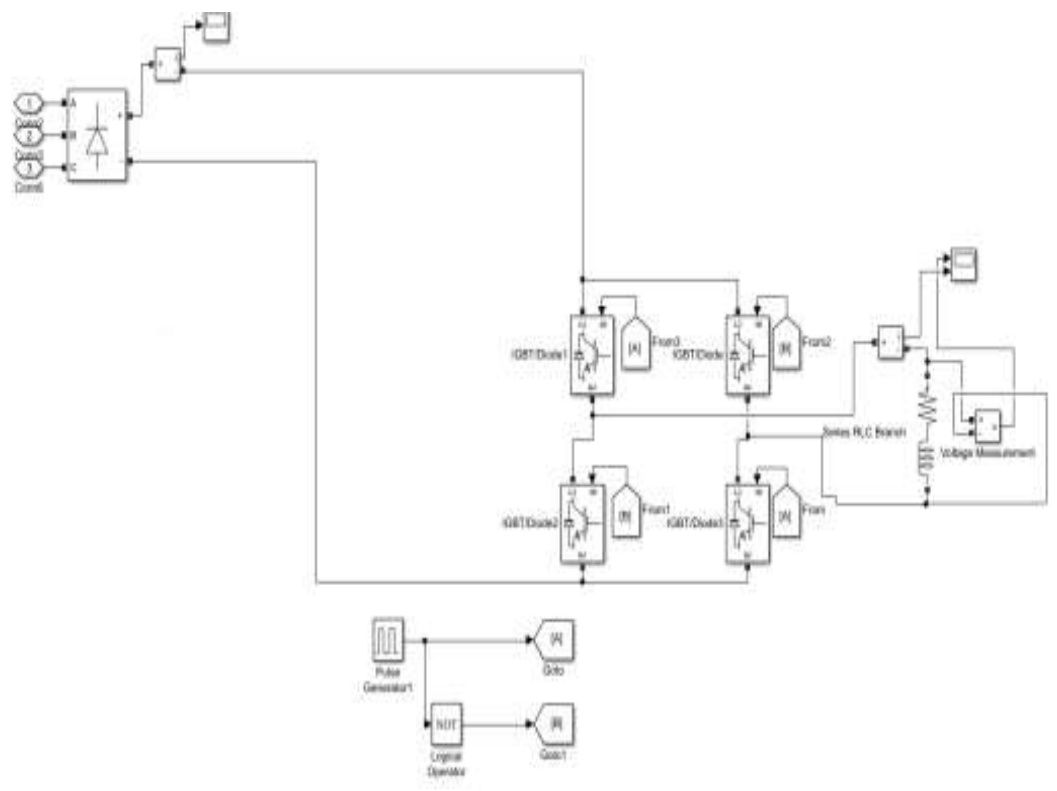

Fig-11 Sub system-3 with inverter load

Fig-11 consist of the inverting circuit connections consisting of controllable rectifiers connected after the rectifier (within sub system 3) of the circuit.

The working of this system includes, in first positive half cycle, A will work and in other half cycle, B will work and accordingly the current and voltage measurement will be shown in scope.

The fig-12 shows the wave form obtained after the inversion of the dc output generated by the rectifier. Table-3 gives the harmonics percentage of the system.

Total $\mathbf{T H D}=\mathbf{2 2 . 7 0 \%}$

Table-3 THD \% for multiple of fundamental frequency

\begin{tabular}{|l|l|}
\hline Frequency & THD \\
\hline $150 \mathrm{HZ}$ & $15.79 \%$ \\
\hline $250 \mathrm{HZ}$ & $7.57 \%$ \\
\hline $350 \mathrm{HZ}$ & $3.29 \%$ \\
\hline $450 \mathrm{HZ}$ & $2.83 \%$ \\
\hline $550 \mathrm{HZ}$ & $2.33 \%$ \\
\hline $650 \mathrm{HZ}$ & $2.03 \%$ \\
\hline $750 \mathrm{~Hz}$ & $1.17 \%$ \\
\hline $850 \mathrm{~Hz}$ & $0.58 \%$ \\
\hline
\end{tabular}

The Total Harmonic Reduction is $27.72 \%$ and $3^{\text {rd }}$ harmonics is $0.22 \%$ and $5^{\text {th }}$ harmonic is $26.76 \%$ and $7^{\text {th }}$ harmonic is $0.50 \%$.

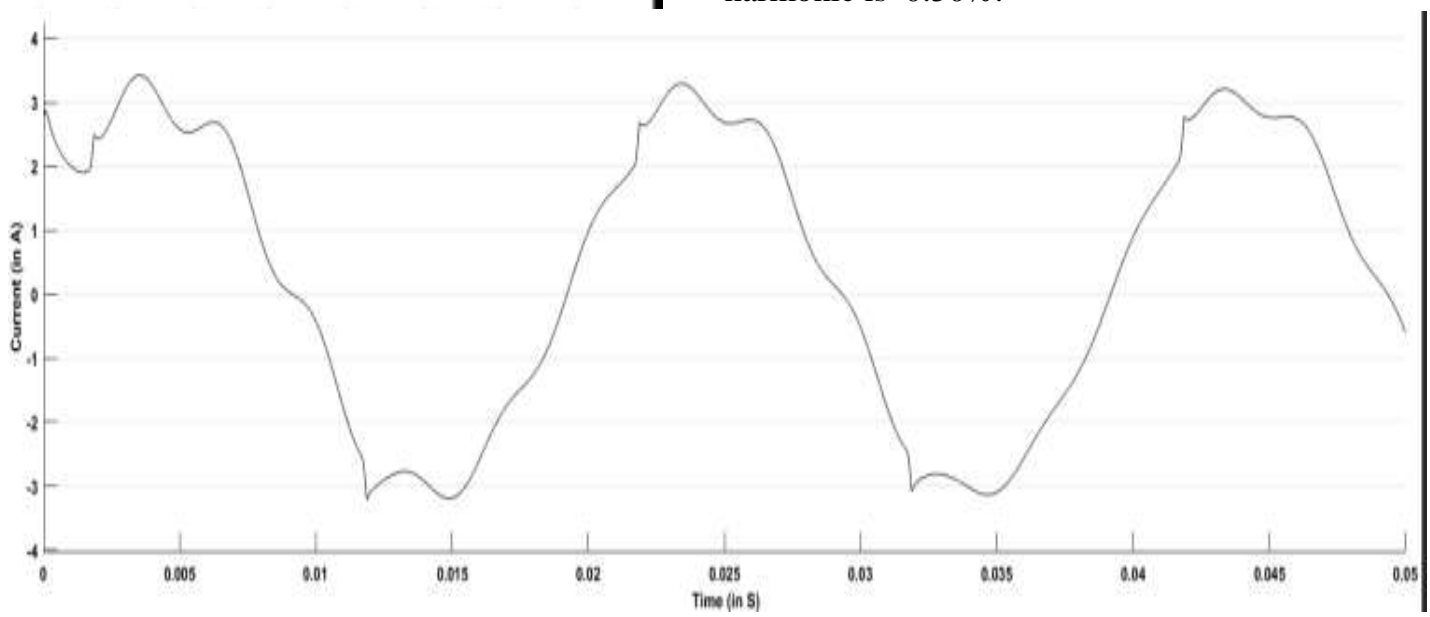

Fig-13 Input Current Graph when connected to Inverter Load 
The distortion in the current waveform shown in graph is due to the presence of the inverting circuit and other line

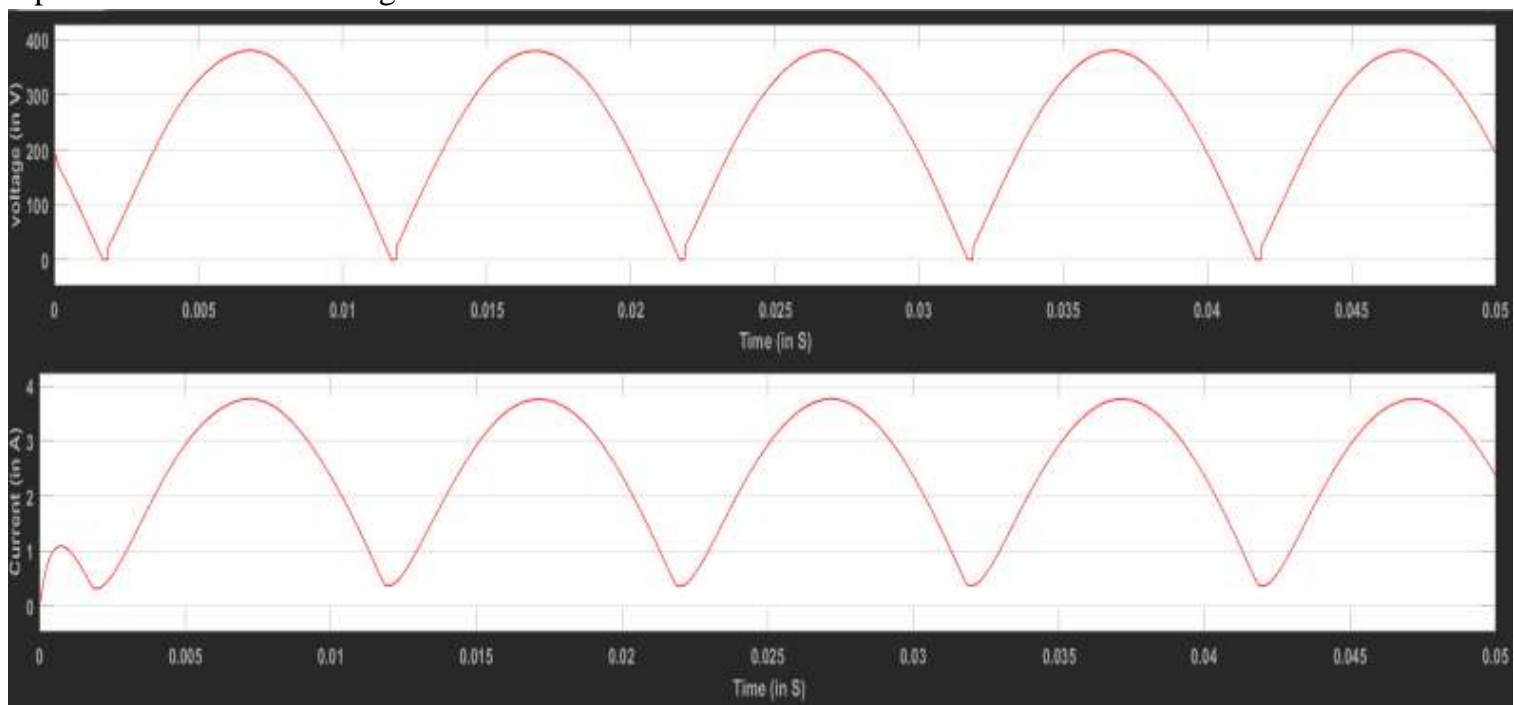

Fig -14 Output voltage and current graphs of inverter

\subsection{Linear Load Without Rectifier Load}

The linear load comprises of resistive and inductive load. The circuit includes voltage source, non linear load, each phase consist of externally attached linear load. Each phase is provided with single tuned filter, voltage measurement and display unit. The output voltage waveform is a proper sinusoidal wave which shows that, the power factor of the circuit is in the proper range.

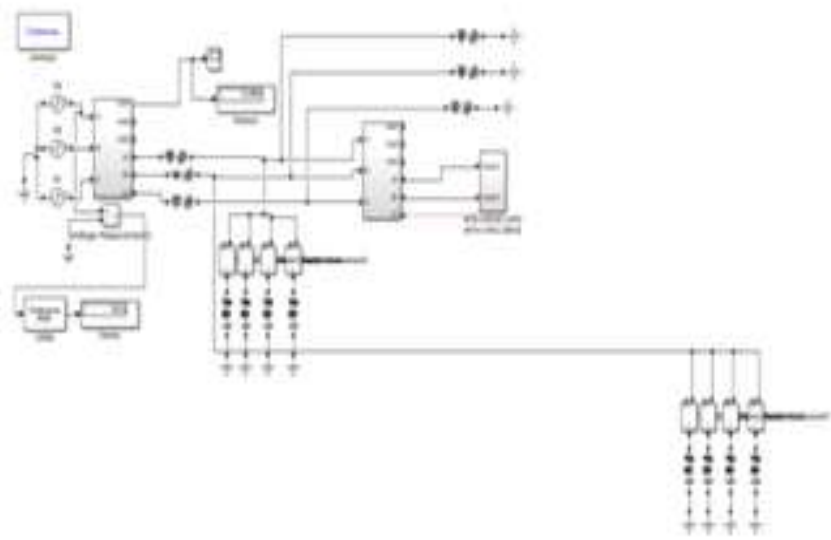

Fig-15 Circuit diagram with Linear Load

The total harmonic distortion value, which we have been obtained is $1.24 \%$, which is much lesser than the other values. The peak fundamental of 3.806 , the THD is $0.07 \%$, whereas the fundamental of 3.81 , THD is 1.24 pure sinusoidal waveform is obtained, because we have not included any reactive load, which intern consist capacitor and inductors. There is no deviation in the power factor value, due to which the other parameters present is kept unaffected, and there is less number of reactive components, due to which there is less load current and less voltage drop across the network. Table-4 give all the THD value of the system.
Total THD $=1.24 \%$

Table-4 THD \% for multiple of fundamental frequency

\begin{tabular}{|l|l|}
\hline Frequency & THD \\
\hline $150 \mathrm{HZ}$ & $0.13 \%$ \\
\hline $250 \mathrm{HZ}$ & $0.16 \%$ \\
\hline $350 \mathrm{HZ}$ & $0.08 \%$ \\
\hline $450 \mathrm{HZ}$ & $0.10 \%$ \\
\hline $550 \mathrm{HZ}$ & $0.10 \%$ \\
\hline $650 \mathrm{HZ}$ & $0.10 \%$ \\
\hline $750 \mathrm{HZ}$ & $0.10 \%$ \\
\hline $850 \mathrm{HZ}$ & $0.11 \%$ \\
\hline $950 \mathrm{HZ}$ & $0.10 \%$ \\
\hline
\end{tabular}

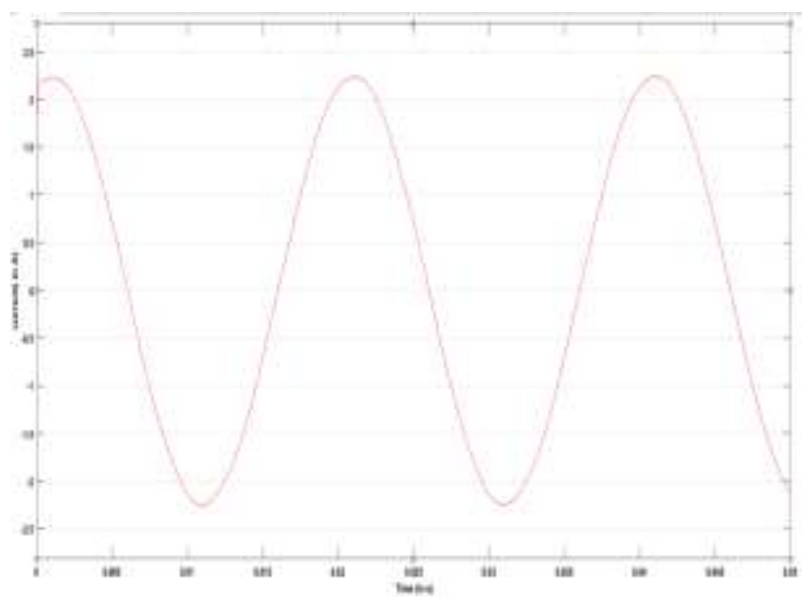

Fig-16 Input Current Waveform

The fig-16 gives the current waveform when only linear load is connected in the system, the graphs shows very little presence of distortion on it.

\subsection{All Machines Connected At Once}

When many machines or components are considered all at once then they have different effect on the harmonics of the system as well as on the total harmonic distortion (THD) of the system. The system is connected with linear load, rectifier

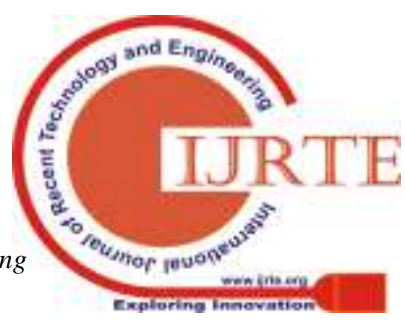




\section{SOURCE HARMONIC REDUCTION USING PASSIVE FILTER IN DIFFERENT NON-LINEAR LOADED CONDITIONS}

load ( filter and resistive load), permanent magnet machine, dc machine, inductive machine.

Total THD $=\mathbf{1 3 . 5 5 \%}$

Table-5 THD \% for multiple of fundamental frequency

\begin{tabular}{|l|l|}
\hline Frequency & THD \\
\hline $150 \mathrm{HZ}$ & $4.92 \%$ \\
\hline $250 \mathrm{HZ}$ & $3.03 \%$ \\
\hline $350 \mathrm{HZ}$ & $2.73 \%$ \\
\hline $450 \mathrm{HZ}$ & $1.79 \%$ \\
\hline $550 \mathrm{HZ}$ & $1.70 \%$ \\
\hline $650 \mathrm{HZ}$ & $1.38 \%$ \\
\hline $750 \mathrm{HZ}$ & $1.20 \%$ \\
\hline $850 \mathrm{HZ}$ & $1.07 \%$ \\
\hline $950 \mathrm{HZ}$ & $0.93 \%$ \\
\hline
\end{tabular}

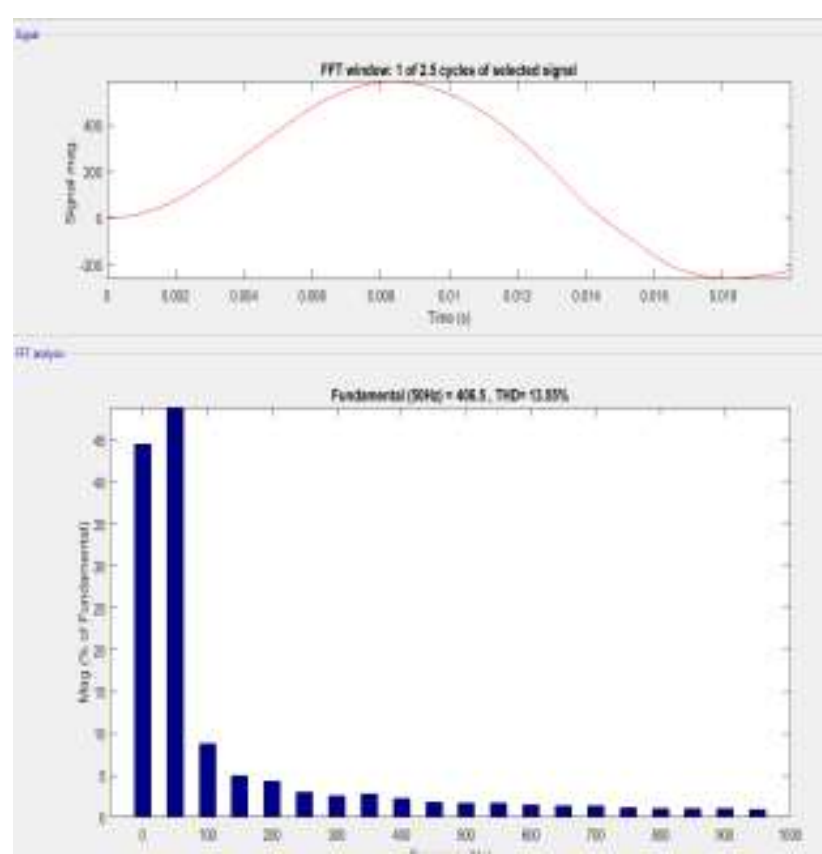

The overall THD of the system seen is $13.55 \%$ and the harmonic peaks are gradually reduced then other machines as compared to other machines. The table- 5 shows the harmonic destitution of the system. Fig-17 shows the harmonic destitution of the system.

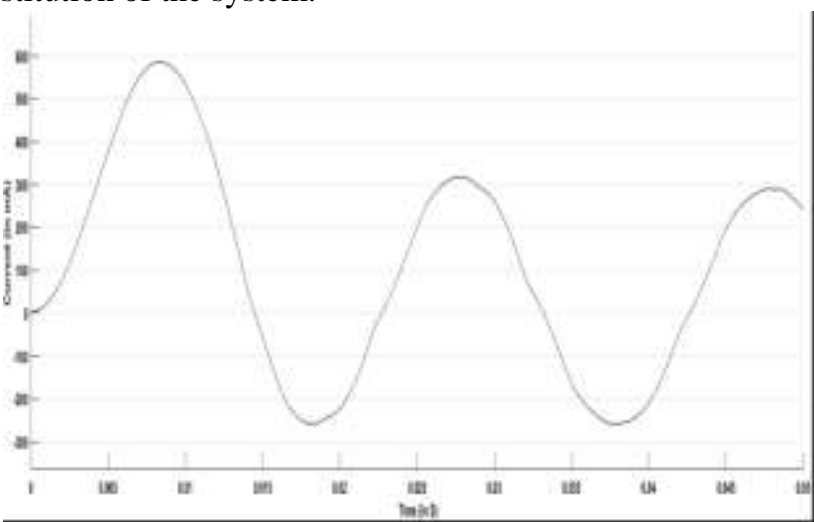

Fig-18 Input current waveform when all machines connected together as load

The current waveform obtained (fig-18) after connecting all the components in series and a shunt register of $100 \mathrm{ohms}$ is connected in parallel for the proper working of the system.

Fig-17 Harmonic Destitution with fundamental

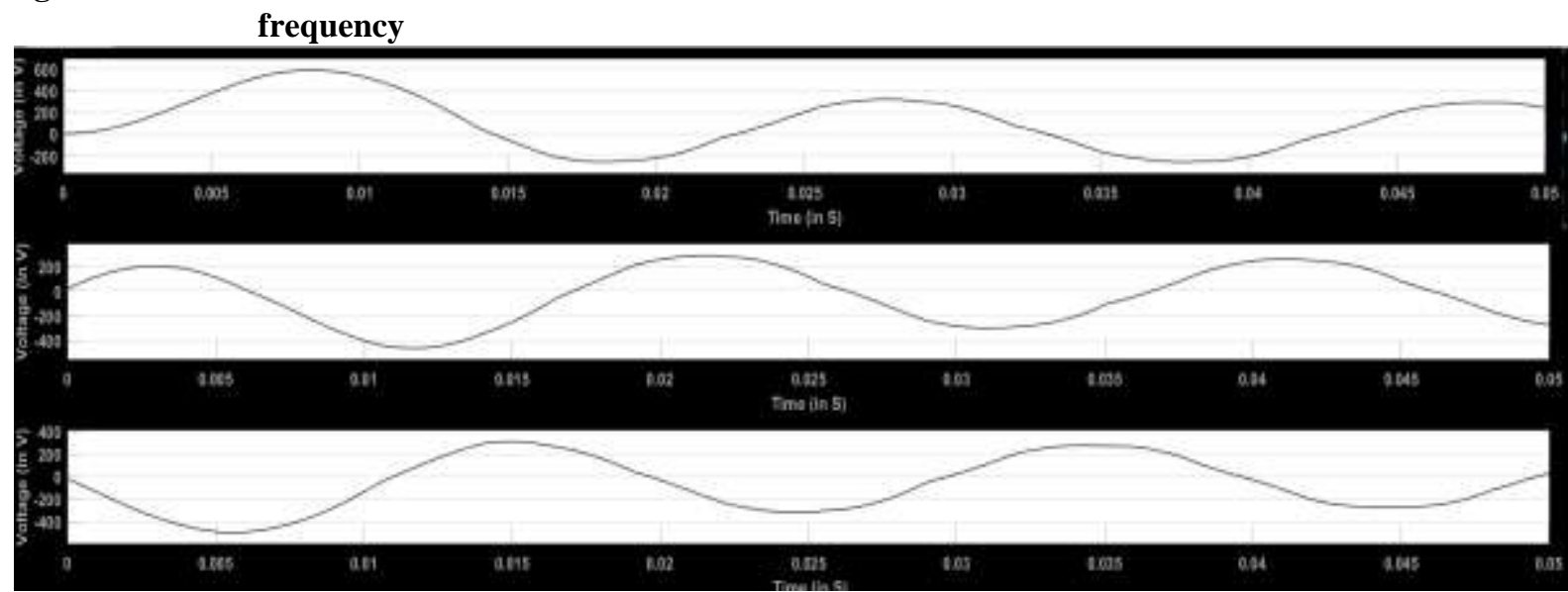

Fig-19 Voltage Waveforms before line reactance and reluctance

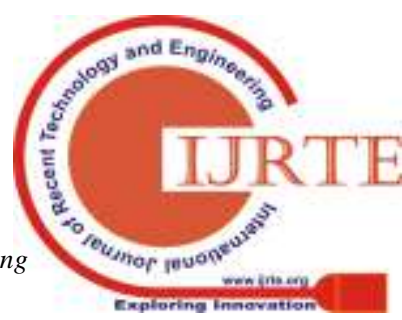




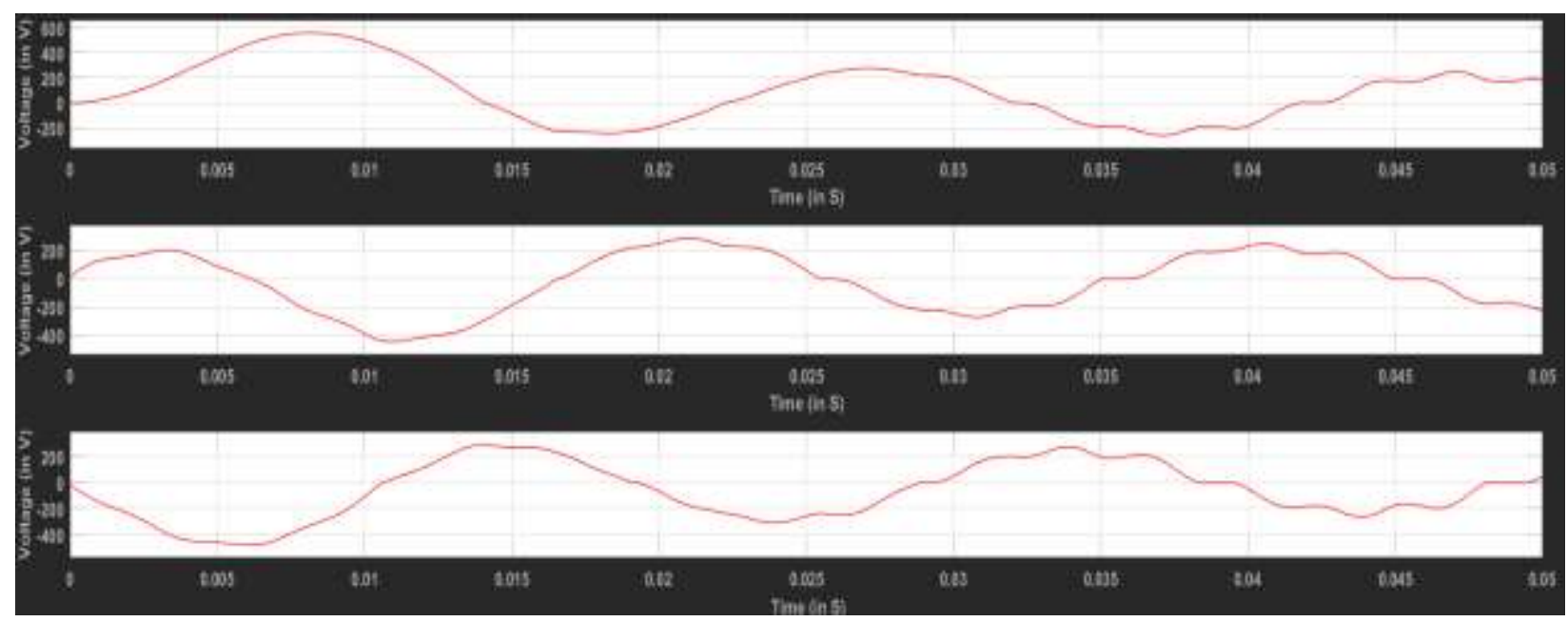

Fig-20 Voltage Waveforms after line reactance and reluctance

Fig-19,20 shows the voltage waveform of every individual phase before and after the line reactance and line reluctance simultaneously. The changes in the waveform is clearly seen, ande these are considered due to the practical parameters of transmission line.

\section{RESULTS}

When these circuits are connected without filters connected to them then a substantial increase in the overall harmonics in the system is seen. When a only the linear load is connected in parallel to the circuit then only a slight increase in the harmonics is shown in tablr-6.

\section{Total THD=1.96}

Table-6 THD \% for multiple of fundamental frequency

\begin{tabular}{|l|l|l|}
\hline Frequency & THD With filter & $\begin{array}{l}\text { THD Without } \\
\text { filter }\end{array}$ \\
\hline $150 \mathrm{HZ}$ & $0.13 \%$ & $1.61 \%$ \\
\hline $250 \mathrm{HZ}$ & $0.16 \%$ & $1.42 \%$ \\
\hline $350 \mathrm{HZ}$ & $0.08 \%$ & $0.93 \%$ \\
\hline $450 \mathrm{HZ}$ & $0.10 \%$ & $0.39 \%$ \\
\hline $550 \mathrm{HZ}$ & $0.10 \%$ & $0.26 \%$ \\
\hline $650 \mathrm{HZ}$ & $0.10 \%$ & $0.26 \%$ \\
\hline $750 \mathrm{HZ}$ & $0.10 \%$ & $0.23 \%$ \\
\hline $850 \mathrm{HZ}$ & $0.11 \%$ & $0.28 \%$ \\
\hline $950 \mathrm{HZ}$ & $0.10 \%$ & $0.23 \%$ \\
\hline
\end{tabular}

In case when all lodes (dc lodes along with ac lodes) are connected all at once then the increase in the Total Harmonic Distortion is comparatively larger than that on connecting it to only linear lode. Table-7 gives the harmonic distortion in the system.

Table-7 THD \% for multiple of fundamental frequency

\begin{tabular}{|l|l|l|}
\hline Frequency & $\begin{array}{l}\text { THD with } \\
\text { Filter }\end{array}$ & $\begin{array}{l}\text { THD Without } \\
\text { Filter }\end{array}$ \\
\hline $150 \mathrm{HZ}$ & $4.92 \%$ & $7.29 \%$ \\
\hline $250 \mathrm{HZ}$ & $3.03 \%$ & $5.48 \%$ \\
\hline $350 \mathrm{HZ}$ & $2.73 \%$ & $5.03 \%$ \\
\hline $450 \mathrm{HZ}$ & $1.79 \%$ & $3.77 \%$ \\
\hline $550 \mathrm{HZ}$ & $1.70 \%$ & $3.59 \%$ \\
\hline $650 \mathrm{HZ}$ & $1.38 \%$ & $3.31 \%$ \\
\hline $750 \mathrm{HZ}$ & $1.20 \%$ & $3.02 \%$ \\
\hline $850 \mathrm{HZ}$ & $1.07 \%$ & $2.84 \%$ \\
\hline $950 \mathrm{HZ}$ & $0.93 \%$ & $2.66 \%$ \\
\hline
\end{tabular}

\section{CONCLUSION}

From the case study, it provides the basic idea about the reduction of harmonics using different filters. In Single tuned filter, the total harmonic reduction is $27.81 \%$ for resistive load, $20.51 \%$ for RLC load, and the peak harmonic value observed at $5^{\text {th }}$ order, is the highest among all. The distortion in the waveform obtained of the output voltage implies that the power factor of the circuit is high. The power factor value of any circuit must be in the range of 0 to 1 ., and if it fulfills the criteria, then the output voltage waveform obtained will be pure sinusoidal. The reactive element present in the circuit distorts the waveform of respective graph. For compensating the distortion, the filters are added, which basically improves the power factor and reduces the value of total harmonic reduction to its minimum value. The THD value of RL load with c filter is $30.42 \%$ and the distortion obtained is high. The linear load with asynchronous motor is $18.61 \%$. and the waveform of the output obtained is pure sinusoidal. The THD obtained for dc motor is $28.09 \%$, which shows that dc motor have high THD value than linear load of asynchronous motor, the heating loss produced due to motor winding changes the value of current which also effects the value of power factor. The THD value of inverter load is $27.72 \%$ and the output voltage obtained is pure sinusoidal waveform. So the harmonic distortion of the linear load without rectifier is the lowest with the value of $1.24 \%$. the waveform formed using this circuit is pure sinusoidal.

\section{REFERENCES}

1. Active Power Management of Electric Power System Using Emerging Power Electronics Technology by Alex Q. Huang ; Subhashish Bhattacharya ; Mesut Baran ; Bin Chen ; Chong Han 2007 IEEE

2. Harmonics Mitigation of Industrial Power System Using Passive Filters by Zubair Ahmed Memon, Mohammad slam Uquaili, and mukhtiar Ali Una, IJPAM 2016.

3. Single-tuned Passive Harmonic Filter Design Considering Variances of Tuning and Quality Factor by Young-Sik Cho \& Hanju Cha, Journal of International Council on Electrical Engineering. 
4. Analysis and estimation of harmonics using passive filters by Serhat Berat Feel, Bitilis Eren J Sci \& Tech.

5. Opeminal Design of Single Tuned Passive Filter Using Surface Methodology by Scekul Sankar, Aslam Deniz Karagolan, Murath Erhan Balci,Aleem, ISNCC 2015.

6. Single- Tuned Passive Harmonic Filter Design with Uncertain Source And Load Characteristics by Hassan A. M. Ali, AhemaD F Zobba, Essam E. A. El., Recent Patents in Electrical Engineering, 2015.

7. Three Tuned Passive Filters to Improve Power Quality by Chen Bo; Zeng Xiangjun; Xv Yao, internal Conference onPower System Technology.

8. Optimal single tuned damped filter for mitigating harmonics using MIDACO by Nor H. B. Abdul Kahar ; Ahmed F. Zobaa

9. A New Method of Design Of Double Tuned Filter by He YI-hong, Su Heng, ICCSEE 2013.

10. Harmonic Mitigation Using Passive Filters by Anmol Patil, Ranjeet Narayan, Patil Arijit, IJETT Vol.-45.

11. Compensates the double tuned filter element parameter change based on the controllable reactor Kang Ming-cai ; Zhou Jia-hua 